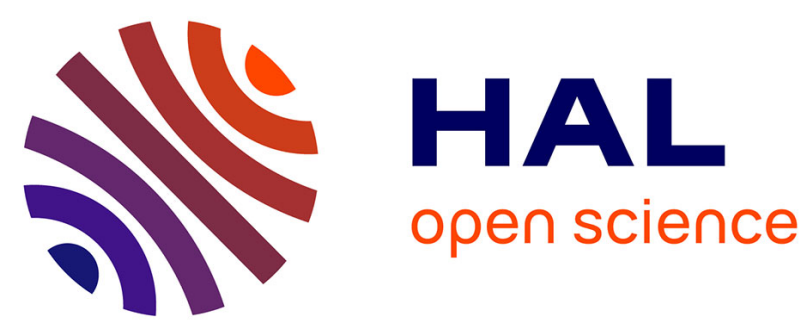

\title{
Bare and Sterically Stabilized PLGA Nanoparticles for the Stabilization of Pickering Emulsions
}

Claire Albert, Nicolas Huang, Nicolas Tsapis, Sandrine Geiger, Véronique

Rosilio, Ghozlene Mekhloufi, David Chapron, Baptiste Robin, Mohamed

Beladjine, Valérie Nicolas, et al.

\section{To cite this version:}

Claire Albert, Nicolas Huang, Nicolas Tsapis, Sandrine Geiger, Véronique Rosilio, et al.. Bare and Sterically Stabilized PLGA Nanoparticles for the Stabilization of Pickering Emulsions. Langmuir, 2018, 34 (46), pp.13935-13945. 10.1021/acs.langmuir.8b02558 . hal-01990240

\author{
HAL Id: hal-01990240 \\ https://hal.science/hal-01990240
}

Submitted on 23 Oct 2019

HAL is a multi-disciplinary open access archive for the deposit and dissemination of scientific research documents, whether they are published or not. The documents may come from teaching and research institutions in France or abroad, or from public or private research centers.
L'archive ouverte pluridisciplinaire HAL, est destinée au dépôt et à la diffusion de documents scientifiques de niveau recherche, publiés ou non, émanant des établissements d'enseignement et de recherche français ou étrangers, des laboratoires publics ou privés. 


\section{Bare and sterically stabilized PLGA nanoparticles}

\section{for the stabilization of Pickering emulsions}

Claire Albert ${ }^{a}$, Nicolas Huang ${ }^{a}{ }^{*}$, Nicolas Tsapis ${ }^{a}$, Sandrine Geiger ${ }^{a, b}$, Véronique Rosilio $^{a}$, Ghozlene Mekhloufi $i^{a}$, David Chapron ${ }^{a}$, Baptiste Robin ${ }^{a}$, Mohamed Beladjine ${ }^{a}$, Valérie Nicolas $^{c}$, Elias Fattal ${ }^{a}$, Florence Agnely ${ }^{a}$

aa Institut Galien Paris-Sud, CNRS UMR 8612, Univ Paris-Sud, Université Paris-Saclay, Faculté de Pharmacie, 5 rue J.B. Clément, 92296 Châtenay-Malabry, France.

${ }^{\mathrm{b}}$ Laboratoire Structures, Propriétés et Modélisation des Solides (SPMS) UMR CNRS 8580, CentraleSupélec, Université Paris Saclay, 3 Rue Joliot Curie, 91190 Gif-sur-Yvette, France.

${ }^{\mathrm{c}}$ Plateforme d'imagerie cellulaire MIPSIT, SFR-UMS-IPSIT, Univ. Paris-Sud, Université ParisSaclay, Faculté de Pharmacie, 5 rue J.B. Clément, Châtenay-Malabry F-92296, France.

*Corresponding Author: N. Huang nicolas.huang@u-psud.fr

KEYWORDS: Pickering emulsion, PLGA, nanoparticles, stability, multiple emulsion, microstructure, interfacial properties 


\begin{abstract}
Pickering emulsions were formulated using biodegradable and biocompatible poly(lacticco-glycolic acid) (PLGA) nanoparticles (NPs) prepared without surfactants or any other polymer than PLGA. A pharmaceutical and cosmetic oil (Miglyol) was chosen as the oil phase at a ratio of $10 \% \mathrm{w} / \mathrm{w}$. These emulsions were then compared with emulsions using the same oil, but formulated with well-described PLGA-PVA NPs, i.e. with poly(vinyl alcohol) (PVA) as NP stabilizers. Strikingly, the emulsions demonstrated very different structures at macroscopic, microscopic and interfacial scales, depending on the type of NPs used. Indeed, the emulsion layer was significantly thicker when using PLGA NPs rather than PLGA-PVA NPs. This was attributed to the formation and coexistence of multiple $\mathrm{W} / \mathrm{O} / \mathrm{W}$ and simple $\mathrm{O} / \mathrm{W}$ droplets, using a single step of emulsification, whereas simple $\mathrm{O} / \mathrm{W}$ emulsions were obtained with PLGA-PVA NPs. The latter NPs were more hydrophilic than bare PLGA NPs because of the presence of PVA at their surface. Moreover, PLGA NPs only slightly lowered the oil/water interfacial tension, whereas the decrease was more pronounced with PLGA-PVA NPs. The PVA chains at the PLGA-PVA NP surface could probably partially desorb from the NPs and adsorb at the interface, inducing the interfacial tension decrease. Finally, independently of their composition, NPs were adsorbed at the oil/water interface without influencing its rheological behavior, possibly due to their mobility at their interface. This work has direct implications in the formulation of Pickering emulsions and stresses the paramount influence of the physicochemical nature of the NP surface into the stabilization of these systems.
\end{abstract}




\section{Introduction}

Emulsions are today widely used in food, pharmaceutical and cosmetic applications, since they allow the encapsulation of an active ingredient in the dispersed phase, to protect it from degradation and to preserve its activity in a sustained manner. ${ }^{1}$ However, emulsions are thermodynamically unstable systems requiring the use of stabilizers for their fabrication and long-term stability. ${ }^{2}$ Until now, emulsions have been mostly stabilized using synthetic surfactants, ${ }^{3}$ which raises direct or indirect toxicity and environmental issues. ${ }^{4}$ In particular, in topical long-term treatment, skin irritation is often observed. ${ }^{5,6}$ New stabilization approaches have been developed such as the use of solid particles instead of surfactants. ${ }^{7-9}$ Such emulsions, also called Pickering emulsions, display a very good stability (sometimes up to several years) thanks to their high resistance to coalescence. ${ }^{10,11}$ Many types of particles (mineral or organic) can be used to prepare Pickering emulsions. ${ }^{12}$ However, most of the emulsions thus produced are not biocompatible and/or not biodegradable, due to the nature of the particles or oil used, which is a crucial issue for cosmetic or pharmaceutical applications.

In this respect, poly(lactic-co-glycolic acid) (PLGA) nanoparticles (NPs) appear as very promising systems. Indeed, PLGA is a well-known biodegradable and biocompatible copolymer currently used in drug delivery to prepare NPs whose degradation and drug release rates can be tuned by varying the PLGA molecular weight or its lactide:glycolide ratio. ${ }^{13}$ Such NPs can be 
obtained by different processes such as nanoprecipitation or emulsion-evaporation that most often require the use of a stabilizing polymer. PLGA-PVA NPs, i.e. PLGA NPs sterically stabilized by poly(vinyl alcohol) (PVA), a non-toxic stabilizing polymer, ${ }^{14}$ have already been largely described. ${ }^{15}$ However, Pickering emulsions stabilized by this type of NPs have only been reported thrice. ${ }^{16-18}$ In these reported studies, though biocompatible oils were tested (isopropyl myristate, sunflower oil or lipiodol, an iodized and radio-opaque oil), thorough physico-chemical characterizations were either conducted with non-biocompatible model oils such as dodecane or octanol, or were lacking. Beside, only few descriptions of the preparation of stabilizer-free PLGA NPs were reported in the literature. ${ }^{19-21}$ To the best of our knowledge, these bare PLGA NPs obtained by nanoprecipitation without any other polymer or surfactant were never used to formulate Pickering emulsions. However, both bare PLGA NPs and PLGA-PVA NPs are interesting for potential pharmaceutical or cosmetic applications as a very low toxicity was observed on THP-1 derived macrophages ${ }^{20}$ with PLGA NPs and PLGA-PVA NPs, and on different lung cells ${ }^{22,23}$ with PLGA-PVA NPs.

In this context, the main objective of this study was to formulate Pickering emulsions using bare PLGA NPs and PLGA-PVA NPs and to evaluate their stability, microstructure and interfacial properties. To specifically assess the influence of PVA, the two types of NPs were prepared with similar sizes, around $200 \mathrm{~nm}$. In a first step, NPs were characterized in terms of size, surface properties, hydrophobicity and mechanical properties. Then, Pickering emulsions were formulated with both types of NPs using Miglyol $812 \mathrm{~N}$ as the oil phase. This oil composed of medium-chain triglycerides was selected as it is widely used in cosmetics and in topical, oral 
or parenteral pharmaceutical preparations (emulsions, solutions or suspensions). ${ }^{14}$ It has numerous advantages such as absorption enhancement, stability against oxidation, non-toxicity, non-irritating and non-inhibition of skin respiration. ${ }^{14}$ We compared the macroscopic, microscopic and interfacial structures of the resulting Pickering emulsions, as well as their stability over 55 days. A thorough physicochemical study was performed to clarify the mechanisms of stabilization with both types of NPs. The interface between the oil and aqueous phases was characterized by confocal microscopy, interfacial tension and interfacial rheology. The NP hydrophobicity was evaluated by contact angle measurements. Such characterizations are particularly interesting both from application but also from fundamental standpoints. Indeed, most previous studies dealing with the adsorption of core-shell particles at an oil-water interface

were performed with a chemically grafted corona of polymer ${ }^{24,25}$ whereas, here, the stabilizing chains of PVA are adsorbed at the particle surface.

\section{Experimental section}

\subsection{Chemicals}

Poly(lactide-co-glycolide) (PLGA, 75:25 ResomerC) RG756, ester ending, inherent viscosity at $25{ }^{\circ} \mathrm{C}$ and $0.1 \%$ in $\mathrm{CHCl} 3: 0.7-1.0 \mathrm{dL} / \mathrm{g}$ according to the supplier) was purchased from Boehringer-Ingelheim (Germany). PLGA-rhodamine $\mathrm{B}$ conjugate $(\mathrm{MW} \approx 30,000 \mathrm{~g} / \mathrm{mol}$ ) was provided by Akina Inc. (USA). Poly(vinyl alcohol) (PVA, molecular weight 30,000$70,000 \mathrm{~g} / \mathrm{mol}, 87-90 \%$ hydrolyzed according to the supplier), and D-trehalose (from 
saccharomyces cerevisiae, $\geq 99 \%$ ) were obtained from Sigma Aldrich (France). Miglyol (812 N), a medium chain triglyceride oil, was purchased from Cremer Oleo GmbH \& Co. (Germany). Iodine $\left(\mathrm{I}_{2}\right)$ and potassium iodide $(\mathrm{KI})$ used to prepare the iodine solution were purchased respectively from Touzart et Matignon (France) and VWR PROLABO (France). Boric acid and calcein came from Sigma (France). Oregon Green was provided by Invitrogen (France). All the solvents (acetonitrile, acetone and dichloromethane) were provided at the highest grade by Carlo Erba (Milan, Italy). Water was purified using a water system ultrapure MilliQ Direct Type 1 (Millipore, resistivity of $18.2 \mathrm{M} \Omega . \mathrm{cm}$, France).

\subsection{NPs preparation}

PLGA-PVA NPs stabilized by using poly(vinyl alcohol) (PVA) were prepared according to the previously described emulsion-evaporation method. ${ }^{22}$ PLGA NPs were prepared, without any other polymer or surfactant, according to the nanoprecipitation method previously reported by Grabowski et al. ${ }^{20}$ The preparation methods are briefly described in Supporting Information 1.

Fluorescently labeled NPs were prepared by replacing the total quantity of PLGA by a mixture of PLGA and a PLGA-rhodamine conjugate at a ratio of 90/10 (w/w) for PLGA-PVArhod NPs and of 99.9/0.1 (w/w) for PLGA-rhod NPs. 


\subsection{NP characterization}

The size distribution and zeta potential of NPs were measured with a Zetasizer (Nano ZS 90, Malvern Instruments, France, $633 \mathrm{~nm}$ He-Ne laser, Smoluchowski equation) operating at $25^{\circ} \mathrm{C}$ with a $173^{\circ}$ scattering angle. The NP suspension was diluted in MilliQ water for size distribution measurements and in a $1 \mathrm{mM} \mathrm{NaCl}$ aqueous solution for zeta potential measurements, until reaching an attenuator value of 6 . For each sample, three measurements were performed.

NP hydrophobicity was determined using contact angle measurements. A layer of NPs was formed by drying (during $15 \mathrm{~h}$ at $25^{\circ} \mathrm{C}$, protected against dust) a $45 \mu \mathrm{L}$ drop of NP suspension in water at $25 \mathrm{mg} / \mathrm{mL}$ deposited on a freshly cleaved mica surface. Contact angle measurements were performed at $20^{\circ} \mathrm{C}$ using the sessile drop method with a pendant drop tensiometer (Tracker, Teclis, France). A $5 \mu \mathrm{L}$ drop of liquid (water or Miglyol) was gently deposited at the colloidal layer surface. The contact angle was then measured by drop shape analysis over time with the apparatus software (Windrop). The presented results are the average of at least 10 measurements.

\subsection{Emulsion preparation}

Emulsions were prepared with an aqueous phase/oil phase ratio of 90/10 (w/w) using an Ultraturrax (IKA T10 basic) at 20,000 rpm for 2 min with a 5G-stainless steel dispersing tool for the emulsification step. The oil phase was Miglyol and different aqueous phases (solutions or NP 
suspensions) were studied: water as a reference, a PVA solution at $2 \mathrm{mg} / \mathrm{mL}$, a trehalose solution at $150 \mathrm{mg} / \mathrm{mL}$, a PLGA NP suspension at a concentration of $25 \mathrm{mg} / \mathrm{mL}$ in water or in a PVA solution $(2 \mathrm{mg} / \mathrm{mL})$, a suspension of previously lyophilized PLGA-PVA NPs at a concentration of $25 \mathrm{mg} / \mathrm{mL}$ in water and a suspension of non-lyophilized PLGA-PVA NPs at a concentration of $25 \mathrm{mg} / \mathrm{mL}$ in water or in a trehalose aqueous solution $(150 \mathrm{mg} / \mathrm{mL})$.

\subsection{Emulsion characterization}

\subsubsection{Stability}

The emulsion stability during storage at $25^{\circ} \mathrm{C}$ and protected from light was evaluated over 55 days by monitoring the destabilization phenomena using a Turbiscan Classic MA 2000 apparatus (Formulation, Toulouse, France). This technique is based on multiple light scattering: a near-infrared light source scans the sample from bottom to top. Backscattered and transmitted intensities versus sample height were obtained at different days (D0, D1, D2, D3, D7, D12, D20, D35 and D55), thus allowing the detection of destabilization phenomena (creaming, sedimentation, flocculation and coalescence), even at an early stage (invisible to the eye). ${ }^{26}$ In the meantime, macroscopic observations were performed by taking pictures of emulsions in Turbiscan glass tubes. The droplet size distributions were determined by laser granulometry on a Mastersizer S apparatus (Malvern Instrument, Orsay, France). Aliquots of the emulsion layer were diluted with the appropriate volume of MilliQ water (in order to obtain an obscuration between 5 and 10\%). Measurements were performed at least in triplicate, using the Fraunhofer 
optical model, on different emulsions at D0, D1 and D55. Results are presented in percentage of the volume distribution.

\subsubsection{Microscopic structure}

The microscopic structure of the emulsions was observed using a confocal scanning laser microscope (inverted Leica TCS SP8-gated STED, Germany) equipped with a WLL laser (488 and $563 \mathrm{~nm}$ excitation wavelengths) using a HC PL APO CS2 63x/1.40 oil immersion objective lens. $20 \mu \mathrm{L}$ were taken from the emulsion layer for these experiments. To prevent the deformation of emulsion droplets, the sample was placed in a curved glass slip with a cover glass slide on the top. The NPs were labeled in red with rhodamine as previously described (see section 2.2). The aqueous phase was labeled in green by re-suspension of the lyophilized PLGAPVA NPs in a $0.08 \mathrm{mg} / \mathrm{mL}$ solution of Oregon green instead of MilliQ water or by the addition of $100 \mu \mathrm{L}$ of calcein solution at $0.4 \mathrm{mg} / \mathrm{mL}$ to the PLGA NP suspension. Red fluorescence was observed with a $600-710 \mathrm{~nm}$ filter under a $563 \mathrm{~nm}$ laser illumination. Green fluorescence was observed with a 500-535 nm filter under a $488 \mathrm{~nm}$ laser illumination. A hybrid detector under a gated mode (0.3-6.5 ns) was used in order to avoid reflection. The green and the red fluorescence emissions were collected under a sequential mode. The pinhole was set at 1.0 Airy unit.

\subsubsection{Interfacial analysis}

To determine the interfacial organization and rheological behavior of the oil/water interface of the emulsions, the interfacial tension $\gamma$, the absolute value of the complex dilatational 
modulus $\left|E^{*}\right|$ as well as the interfacial elastic E' and viscous E" moduli were measured using the pendant drop tensiometer. A drop of the aqueous phase was formed (with an $18 \mathrm{G}$, straight needle and a $500 \mu \mathrm{L}$ syringe) into Miglyol. Sinusoidal oscillations were applied to the drop volume with a $60 \mathrm{~s}$ period and a variation of $10 \%$ volume at $25^{\circ} \mathrm{C}$ corresponding to the linear regime. The oscillations were started $1800 \mathrm{~s}$ after the drop formation to allow the initial structuration of the interface without any disturbance due to the oscillations. The results presented are the average \pm standard deviation of at least three measurements.

\section{Results and discussion}

\subsection{NP formulation and characterization}

Bare PLGA NPs and PLGA-PVA NPs were prepared. Their properties were first thoroughly assessed and compared. As shown in Table 1, all NPs exhibited narrow size distributions as all PdI values were below $0.1 .^{27}$ PLGA NPs were $170 \mathrm{~nm}$ in hydrodynamic diameter, and slightly smaller than PLGA-PVA NPs. The difference in size between the two types of NPs might be explained by the use of two different methods of preparation and by the presence of the hydrated PVA layer on PLGA-PVA NP surface, which should increase the hydrodynamic diameter. The presence of PVA on the surface could also explain the differences in zeta potential measurements: - $35 \mathrm{mV}$ for PLGA NPs and - $4 \mathrm{mV}$ for PLGA-PVA NPs. Very

likely, the negative charges of PLGA, due to its carboxylic end groups, are screened by PVA, a neutral polymer, resulting in the reduction of zeta potential values. Indeed, the amount of PVA 
associated to PLGA-PVA NPs was quantified at $8 \%$ (w/w of PLGA) of PVA in PLGA-PVA NPs (see Supporting Information 2) and these PVA chains were found to be at the NP surface (see Supporting Information 3).

\begin{tabular}{lccc}
\hline NPs & $\begin{array}{c}\text { Hydrodynamic } \\
\text { diameter }(\mathbf{n m})\end{array}$ & PdI & $\begin{array}{c}\text { Zeta potential } \\
\text { (mV) }\end{array}$ \\
\hline PLGA & $170 \pm 5$ & 0.04 & $-35 \pm 2$ \\
PLGA-PVA & $215 \pm 10$ & 0.06 & $-4 \pm 1$ \\
lyophilized PLGA-PVA & $220 \pm 15$ & 0.08 & $-4 \pm 1$ \\
\hline
\end{tabular}

Table 1. Physico-chemical properties of NPs.

PLGA-PVA NPs were lyophilized using trehalose as a cryoprotectant without any significant change in their size and zeta potential (Table 1). Lyophilization is useful for NP storage following their preparation. However, it was impossible to preserve these properties when lyophilizing PLGA NPs despite the presence of trehalose because of the aggregation of NPs, even after resuspension.

Assuming a molecular weight $\mathrm{M}=50,000 \mathrm{~g} / \mathrm{mol}$ for PVA chains and a density of $1,3 \mathrm{~g} / \mathrm{cm}^{3}$ for NPs), ${ }^{28}$ it was possible to estimate the average area occupied by a PVA chain at the surface of the PLGA-PVA NPs. The obtained value $\left(\approx 22 \mathrm{~nm}^{2}\right)$ was in good agreement with the one reported by Gyulai and Kiss ${ }^{21}\left(\approx 20 \mathrm{~nm}^{2}\right)$ for a Pluronic F27 chain at the surface of PLGA NPs . The radius of gyration, $\mathrm{R}_{\mathrm{g}}$, of a PVA coil in water (good solvent conditions) was calculated 
from the Flory equation $\left(R_{g}=1 / \sqrt{6} \times N^{3 / 5} a\right)$ with $\mathrm{N}$ the number of segments in the PVA chain and $a$ the size of the PVA segment $(0.37 \mathrm{~nm}) .{ }^{29}$ As $\mathrm{R}_{\mathrm{g}}(\approx 10 \mathrm{~nm})$ was higher than the average distance between PVA chains at the particle suface $(\approx 5 \mathrm{~nm})$, the corona of PVA around the PLGA-PVA NPs was expected to be dense in water and its thickness to be higher than $10 \mathrm{~nm}$.

The Young's moduli of the NPs were assessed by AFM measurements (see Supporting Information 4). In the light of these results, no significant deformation of the core of the PLGAPVA and of the PLGA NPs at the oil/water interface was expected (Young's moduli $\approx 8 \mathrm{GPa}$ and $\approx 4 \mathrm{GPa}$, respectively), contrarily to what was observed with nanogels (Young's modulus between $\approx 1$ and $35 \mathrm{MPa}) .{ }^{9}$ A similar assumption was made by Gyulai and Kiss with bare PLGA NPs and PLGA NPs sterically stabilized by Pluronic F127. ${ }^{21}$

NP hydrophobicity was evaluated by measuring the contact angle of a drop of liquid (water or Miglyol) deposited in the air on top of a NP layer adsorbed onto a mica substrate (Table 2). As seen in AFM pictures, the NP layers covered the substrate as a dense particle layer with a low roughness, similar for PLGA NPs and the non-lyophilized PLGA-PVA NPs (see Supporting Information 4). The contact angle value was recorded $0.4 \mathrm{~s}$ after droplet deposition, to avoid any imbibition effects (see Supporting Information 5). The NPs were soluble neither in water nor in Miglyol and kept their integrity, although PLGA chains were not chemically crosslinked. 


\begin{tabular}{|c|c|c|}
\hline & \multicolumn{2}{|c|}{ Contact angle $\left(^{\circ}\right)$} \\
\hline liquid & Water & Miglyo \\
\hline Without NPs & $<0.2$ & $38 \pm 6$ \\
\hline PLGA NPs & $120 \pm 5$ & $18 \pm 2$ \\
\hline PLGA-PVA NPs & $82 \pm 7$ & $17 \pm 2$ \\
\hline
\end{tabular}

Table 2. Contact angles measured on a NP colloidal layer on a mica substrate at $\mathrm{t}=0.4 \mathrm{~s}$ (number of independent measurements: $\mathrm{n}=10$ at least).

Both types of NPs presented a lower contact angle with Miglyol than with water: the colloidal layers were more hydrophobic than hydrophilic. With water, the contact angle for PLGA-PVA NPs $\left(\approx 82^{\circ}\right)$ was lower than for PLGA NPs $\left(\approx 120^{\circ}\right)$ : the PLGA-PVA NP layer was slightly more hydrophilic than the PLGA NP layer. This difference of hydrophilicity is due to the presence of PVA at the surface of PLGA-PVA NPs, since PVA is a more hydrophilic polymer than PLGA. ${ }^{30}$ Surprisingly, the contact angles with Miglyol were identical for PLGA NPs and PLGA-PVA NPs $\left(\approx 17^{\circ}\right)$ : PVA had no influence on the wettability of the NPs by Miglyol. An interpretation of this phenomenon is given in section 3.5.2.

This physicochemical characterization showed that the NPs were in the same size range but were different in terms of zeta potentials, Young's moduli and hydrophobicity. This difference was mostly attributed to the PVA at the PLGA-PVA NP surface. Emulsions stabilized by one or the other type of NPs were then formulated and compared. 


\subsection{Emulsion formulation}

Emulsions at a 90/10 aqueous phase/oil phase (w/w) ratio were formulated with Miglyol as the oil phase and with, as the aqueous phase, a suspension in water at $25 \mathrm{mg} / \mathrm{mL}$ of either lyophilized PLGA-PVA NPs (Figure 1a) or PLGA NPs (Figure 1b). This particular aqueous phase/oil phase ratio was chosen in order to have a sufficient amount of NPs to stabilize the oil/water interface. Both resulting emulsions were very different in their macroscopic aspect. After a creaming step, the emulsion stabilized with PLGA-PVA NPs exhibited a thin emulsion layer $(\approx 7 \mathrm{~mm})$ on top of the sample with a cloudy aqueous phase, due to an excess of NPs. The emulsion stabilized with PLGA NPs exhibited a significantly thicker emulsion layer $(\approx 21 \mathrm{~mm})$ on top of a clear aqueous phase. This difference was consistent with the previous observation that PLGA-PVA NPs were more hydrophilic than PLGA NPs (see section 3.1). The oil had no inherent stabilizing properties as the mixture of Miglyol and water only, used as a control, phase separated within minutes (Figure 1c).

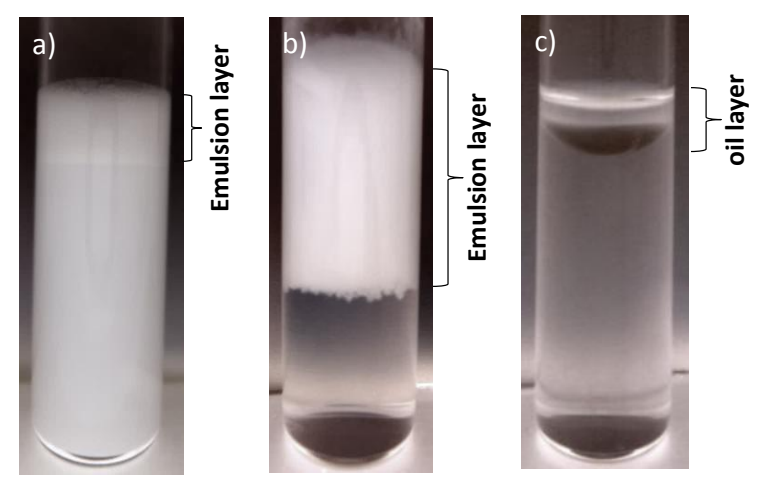


Figure 1. Images at D7 of emulsions containing $10 \%(w / w)$ of Miglyol and a) $90 \%(w / w)$ of lyophilized PLGA-PVA NP suspension at $25 \mathrm{mg} / \mathrm{mL}$ in water, b) $90 \%$ (w/w) of PLGA NP suspension at $25 \mathrm{mg} / \mathrm{mL}$ in water and c) $90 \%(\mathrm{w} / \mathrm{w})$ of water.

The stability of these three emulsions, stored at $25^{\circ} \mathrm{C}$ without light over 55 days, was then evaluated with a Turbiscan apparatus.

\subsection{Emulsion stability study}

The evolution of the Turbiscan curves with time provided information on the stability or the destabilization phenomena such as creaming or sedimentation and coalescenceflocculation. $^{26,31}$ Examples of Turbiscan curves obtained for the emulsion stabilized by lyophilized PLGA-PVA NPs are given in Supporting Information 6. From the Turbiscan curves of each emulsion combined with the macroscopic observations performed at the same time, it was possible to construct a scheme summarizing the evolution of the emulsion layer for the different formulations (Figure 2a). The creaming step observed for each emulsion would not be a problem for a pharmaceutical or a cosmetic application provided that the droplet size remained constant. Indeed, if there is no evolution of the droplet size, creaming is a reversible phenomenon which can be bypassed by shaking the sample before use. ${ }^{32}$ 


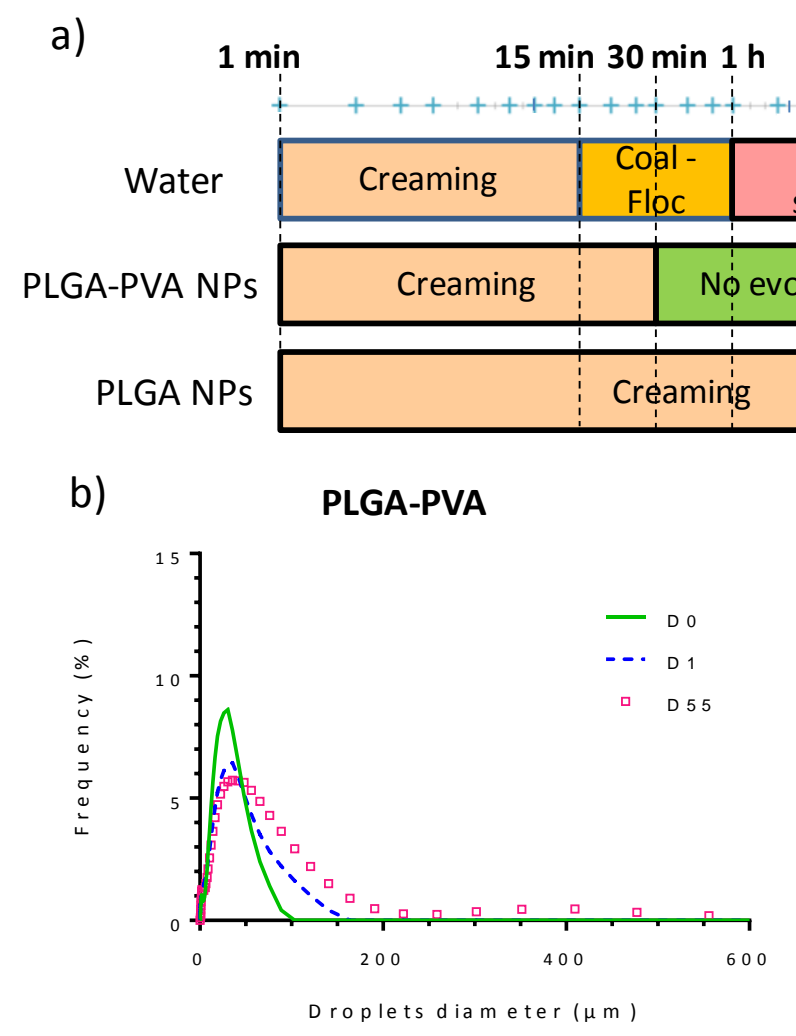

$6 \mathrm{~h} 12 \mathrm{~h} 1 \mathrm{~d}$

$55 \mathrm{~d}$

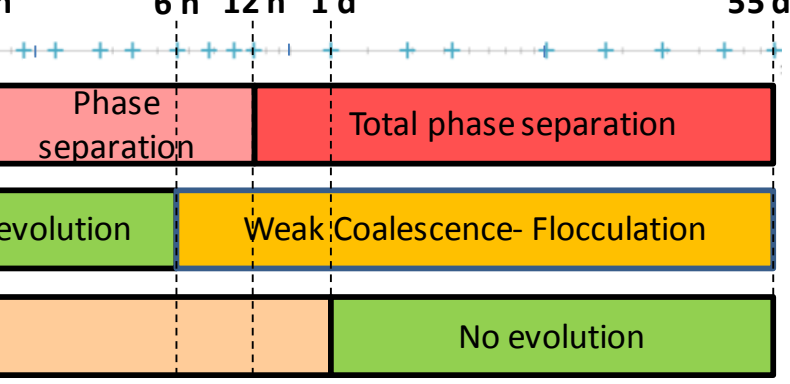

b) c)

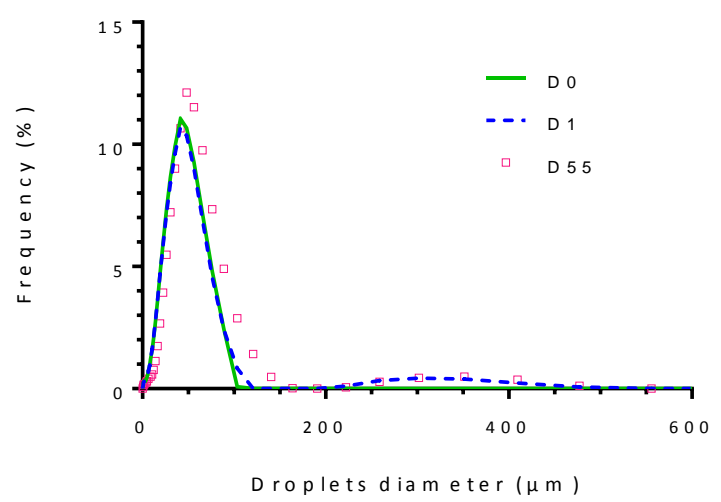

Figure 2. a) Scheme summarizing the evolution of the emulsion layer as determined by Turbiscan analysis of emulsions composed of $10 \%$ of Miglyol and $90 \%$ of water or of a suspension of lyophilized PLGA-PVA NPs or of PLGA NPs both at $25 \mathrm{mg} / \mathrm{mL}$ in water. Time is indicated on a logarithmic scale. b) and c) Volume distribution of droplets diameters measured by laser granulometry at D0, D1 and D55 for emulsions composed of 10\% of Miglyol and 90\% of b) lyophilized PLGA-PVA NP suspension at $25 \mathrm{mg} / \mathrm{mL}$ in water and c) PLGA NP suspension at $25 \mathrm{mg} / \mathrm{mL}$ in water.

Figures $2 \mathrm{~b}$ and $\mathrm{c}$ display the droplet size distributions in the emulsion layer obtained by laser granulometry over time for the two kinds of NP stabilized emulsions. With lyophilized 
PLGA-PVA NPs (Figure 2b), a slight increase in size and polydispersity was observed between D0 and D55, corresponding to the weak coalescence-flocculation mechanism observed by Turbiscan analysis (Figure 2a). Moreover, NP lyophilization did not influence emulsion stabilization: no difference in stability and in macroscopic structure was noticed between the emulsions stabilized either by lyophilized PLGA-PVA NPs or by non-lyophilized PLGA-PVA NPs (Supporting Information 7). Consequently, the emulsions for studies hereunder were prepared using lyophilized PLGA-PVA NPs. For the emulsion stabilized with PLGA NPs (Figure 2c), no significant change in the droplets size was noticed over time: after the creaming stage, no evolution of the emulsion was observed for 55 days at least.

\subsection{Microstructure of the emulsions}

The emulsions stabilized by bare PLGA NPs or by lyophilized PLGA-PVA NPs appeared very different in their macroscopic structure and stability: the presence of PVA adsorbed on the NPs strongly modified the emulsions obtained. Therefore, to better understand these differences, their microscopic structure was studied by confocal scanning laser microscopy. In the confocal microscopy images (Figure 3a and b), NPs appear in red (rhodamine), the aqueous phase in green (Oregon green or calcein) and the Miglyol phase in black. 
a)

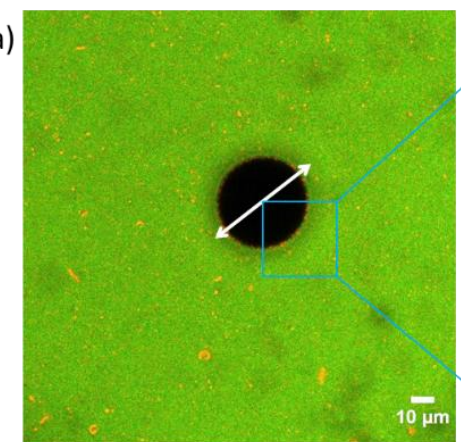

b)

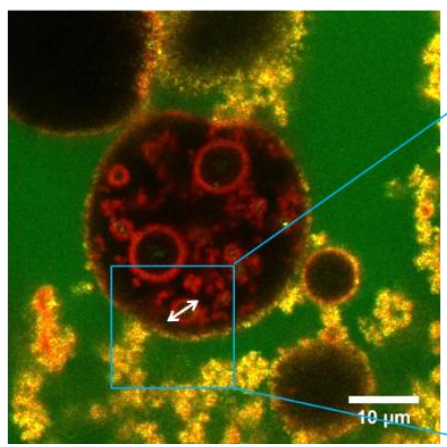

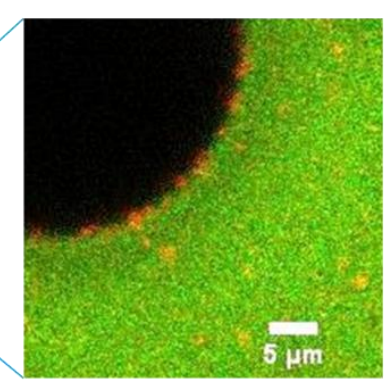
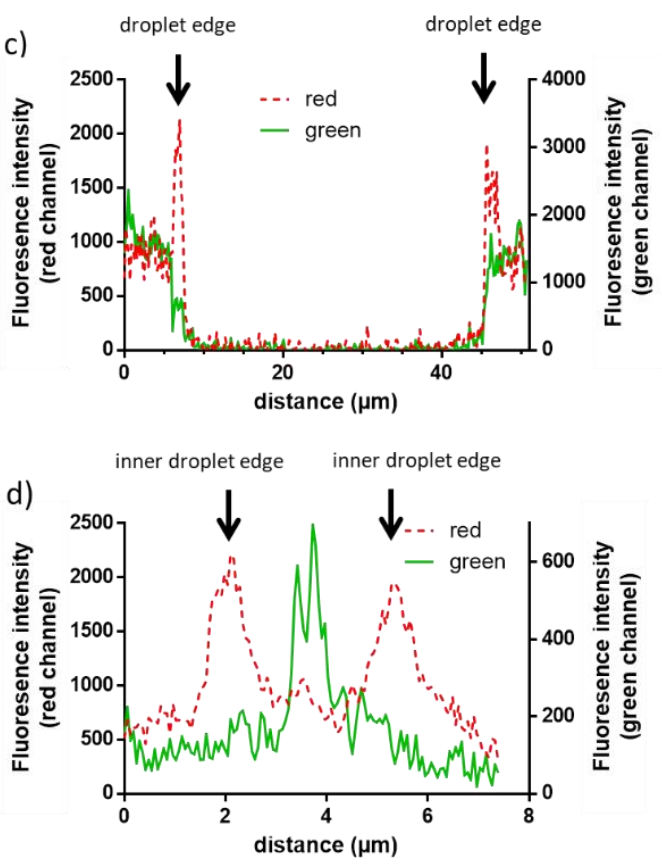

Figure 3: a) and b) Confocal microscopy images of emulsions (green channel: aqueous phase; red channel: NPs) at $10 \%$ of Miglyol and $90 \%$ of a) lyophilized PLGA-PVA NP suspension at $25 \mathrm{mg} / \mathrm{mL}$ in water and b) PLGA NP suspension at $25 \mathrm{mg} / \mathrm{mL}$ in water. c) and d) fluorescence intensity profile of red and green channels of c) a droplet and d) an inner droplet determined along the white oblique line on image a) and b), respectively.

The emulsion stabilized with lyophilized PLGA-PVA NPs was a simple oil in water $(\mathrm{O} / \mathrm{W})$ emulsion as the oil formed droplets in the aqueous phase (Figure 3a). NPs surrounded the oil droplets, confirming that NPs adsorbed at the interface to stabilize the emulsion. NPs were also present in excess in the aqueous phase as previously observed at the macroscopic scale (Figure 1a). The graph giving the fluorescence intensity collected in both channels (green and red) (Figure 3c), measured along the white oblique line of Figure 3a, supports these observations. 
Indeed, two peaks were detected at the edge of the droplet in the red channel, corresponding to the NPs adsorbed at the interface. The fluorescence intensity in the red channel was not null in the aqueous phase of the emulsion layer due to the presence of NPs, whereas the fluorescence intensity in both channels, red and green, was null inside the droplet and not null outside, as expected for simple $\mathrm{O} / \mathrm{W}$ emulsions. All these results were consistent with the macroscopic observations.

In contrast, the microscopic structure of the emulsion stabilized by PLGA NPs was completely different. Figure $3 \mathrm{~b}$ shows the presence of both multiple $\mathrm{W} / \mathrm{O} / \mathrm{W}$ and simple $\mathrm{O} / \mathrm{W}$ droplets. All the droplets were surrounded by NPs and there were some NP aggregates in the aqueous phase of the emulsion layer. The type of multiple droplets was determined by the fluorescence intensity graph (Figure 3d) measured along the white oblique line on Figure 3b. The two peaks in the red channel at the edge of the internal droplet corresponded to the NPs adsorbed at the interface, whereas the peak in the green channel confirmed the presence of water inside the inner droplets. Thus, the multiple droplets were water in oil in water $(\mathrm{W} / \mathrm{O} / \mathrm{W})$.

The presence of multiple droplets is remarkable as usually, to obtain a multiple Pickering emulsion, two emulsification steps are required, using two types of NPs. The more hydrophilic ones stabilize the $\mathrm{O} / \mathrm{W}$ droplets and the more hydrophobic ones stabilize the W/O ones. ${ }^{7,33-37}$ Here, a stable multiple emulsion was obtained using a single emulsification step and only a single type of NPs. Clearly, all the droplets were surrounded by NPs, confirming that the PLGA NPs were able to adsorb at the interface of both droplets: O/W and W/O. Since the first description of 
Pickering multiple emulsions obtained in a single step with silica NPs by Binks \& Rodrigues in $2003,{ }^{38}$ several types of NPs were used: silica NPs, ${ }^{39-41}$ poly(dodecyl acrylate-co-acrylic acid) NPs, ${ }^{42}$ boehmite alumina powder ${ }^{43}$ graphene oxide or silver NPs coated graphene oxide, ${ }^{44,45}$ silicone microbowls ${ }^{46}$ PDMA-PMMA coated latex ${ }^{47}$ and styrene/acid acrylic Janus particles. ${ }^{48}$ The mechanism for the formation of multiple Pickering emulsions obtained in a single step using one type of NPs only was not clearly defined. In these previous studies, four main hypotheses were proposed to explain the formation of a multiple emulsion in a single step using only one type of NPs: (1) a three-phase contact angle at the oil, NPs and water interface around $90^{\circ}$, so that the NPs can adsorb both at the oil/water and the water/oil interfaces; ${ }^{42,43}$ (2) a variation of hydrophobicity inherent to the NPs, so that the most hydrophobic ones would adsorb at the water/oil interface while the most hydrophilic ones would adsorb at the oil/water interface; ${ }^{45}$ (3) a variation of hydrophobicity among the NPs due to their interactions with the liquid they first establish contact; ${ }^{40,46,49}$ (4) the proximity to the phase inversion: just before becoming the dispersed phase, the continuous phase would form some droplets in the drops of the other liquid. 40,46,49,50 Binks et al. ${ }^{39}$ proposed that the multiple emulsion formation would be due simultaneously to a three-phase contact angle around $90^{\circ}$ and to the proximity with the phase inversion (hypotheses 1 and 4). He et al. ${ }^{44}$ also showed that parameters such as particles concentration, oil/water ratio, salt concentration or $\mathrm{pH}$ had an influence on the type of the emulsion (simple or multiple). The mechanism of the formation of such double emulsions is thus complex and is not fully elucidated yet. In the present study, the third hypothesis was unlikely to occur as PLGA NPs were all initially dispersed in water. Besides, a very low oil fraction could 
not explain the presence of multiple droplets, as multiple emulsions were also observed at significantly higher oil ratios. However, it was shown that when increasing the oil ratio, the number of multiple droplets increased until reaching the phase inversion (Supporting Information 8). Thus, for our system, among the hypotheses discussed above, the formation of multiple droplets might involve a three-phase contact angle around $90^{\circ}$, an inherent variation of hydrophobicity among the NPs and/or the proximity with the phase inversion.

The presence of multiple droplets in the emulsion stabilized by PLGA NPs could explain the higher emulsion layer observed compared to the simple $\mathrm{O} / \mathrm{W}$ emulsion stabilized with lyophilized PLGA-PVA NPs. Indeed, with multiple droplets, a higher amount of water participated in the emulsion layer, since some water was also entrapped as small droplets within the oil globules.

Thus, the macroscopic and microscopic structures and the stability of the two emulsions were very different, even though they were prepared with the same oil phase, the same aqueous phase/oil phase ratio of 90/10 (w/w) and the same quantities of NPs in the aqueous phase. The only difference was the type of PLGA NPs (PLGA-PVA NPs or bare PLGA NPs). To further elucidate these differences, an interfacial study was conducted.

\subsection{Interfacial analysis}

The interfacial properties of the NPs at the oil/water interface were investigated with the oscillating pendant drop method. The interfacial tension $(\gamma)$ (Figure $4 \mathrm{a}$ ) as well as the interfacial 
elastic (E') (Figure 4b) and viscous (E”) (Figure 4c) moduli were recorded over 12 hours. For this purpose, a drop of aqueous phase was formed in Miglyol. The values of $\gamma, E^{\prime}, E^{\prime \prime}$ and $\left|E^{*}\right|$ (absolute value of the complex dilatational modulus) at 12 hours for all the samples are summarized in Supporting Information 9. All NP suspensions were prepared at a PLGA concentration of $25 \mathrm{mg} / \mathrm{mL}$.
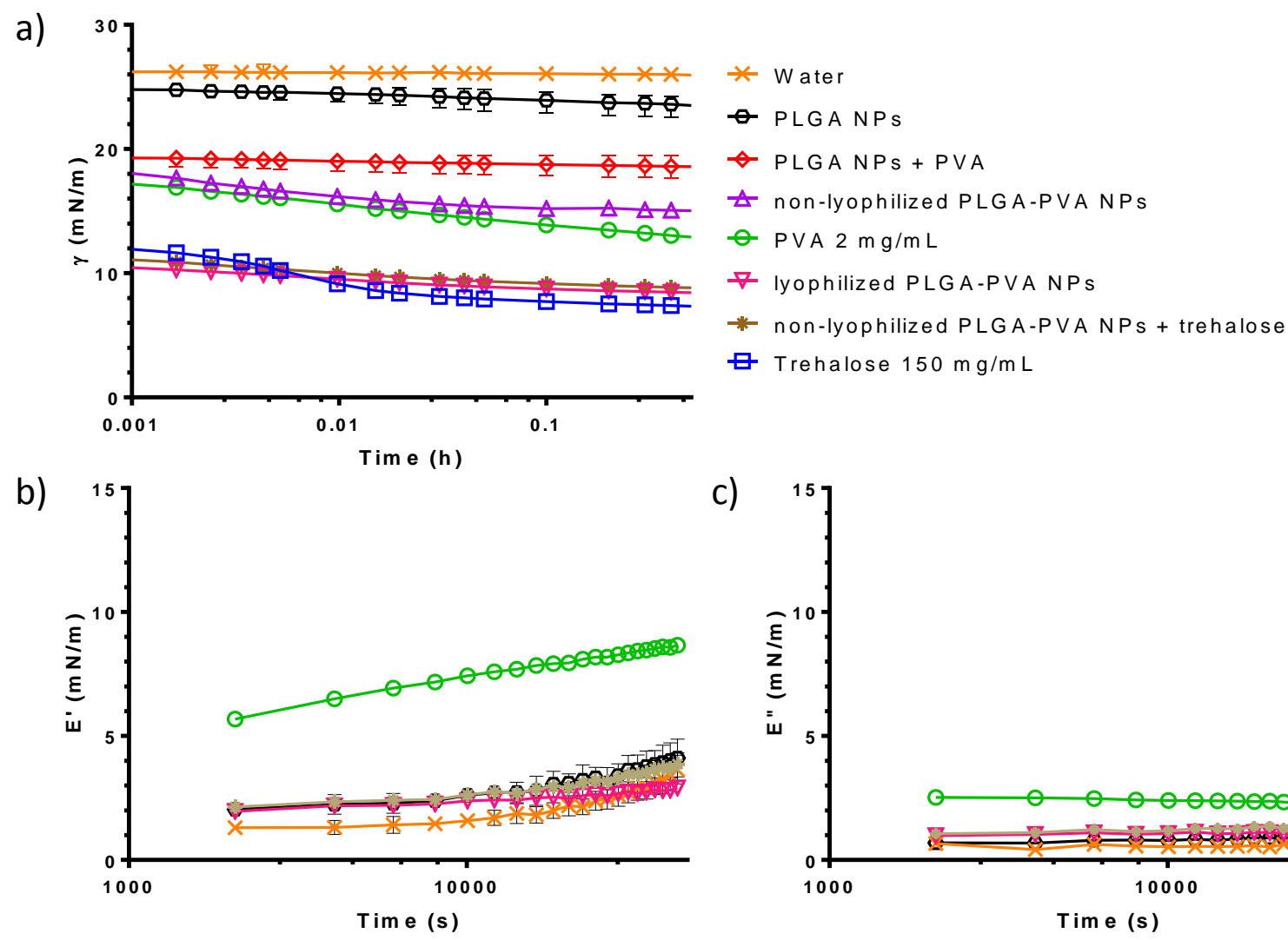

c)

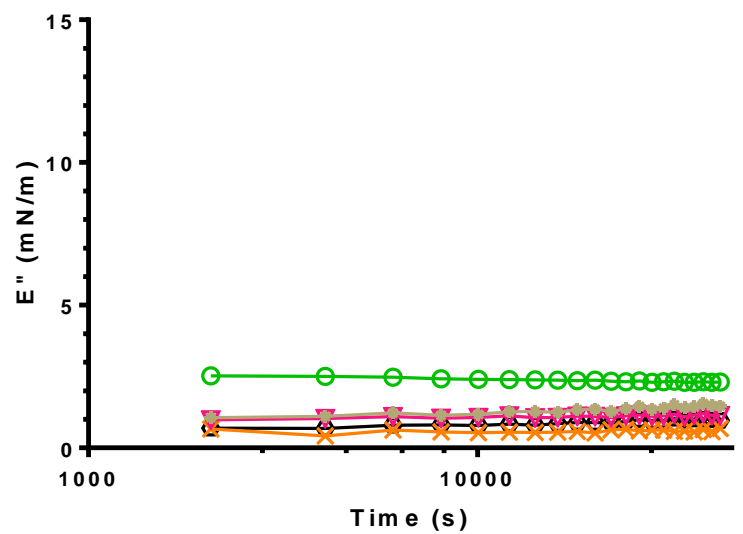

Figure 4. a) Interfacial tensions $\gamma$ b) interfacial elastic moduli E' and c) interfacial viscous moduli E" versus time at $25^{\circ} \mathrm{C}$. Oscillations of $10 \%$ in volume of the drop on a period of $60 \mathrm{~s}$. 
The concentration of the NP suspensions was $25 \mathrm{mg} / \mathrm{mL}$. For some systems, error bars are too small to be visible.

When the aqueous phase was a suspension of PLGA NPs in water, a slight decrease of the interfacial tension was noticed compared to the control (water) (Figure 4a). This is consistent with the work of Gyulai and Kiss ${ }^{21}$ who reported the thermodynamically favorable adsorption and the surface activity of bare PLGA NPs at air/water and octane/water interfaces both with a drop tensiometer and a Langmuir trough. On the other hand, when the aqueous phase was a suspension of PLGA-PVA NPs in water (lyophilized or not), the interfacial tension was significantly lowered compared to the interfacial tension of the water-Miglyol interface without any stabilizer (Figure 4a). We investigated the adsorption kinetics of the NPs at the interface according to a model developed by Bizmark et $a .^{51}$ and also used by Nelson et $a l .^{52}$ (see Supporting Information 10). According to this model, we found that the adsorption energy barrier $\left(\sim 10-15 k_{B} T\right)$ was negligible compared to the adsorption energy of a single NP $\left(\sim 10^{3}-10^{4} k_{B} T\right)$. Consequently, the interface could be considered as barrier-free. The NP adsorption kinetics was mainly governed by diffusion and the NPs were irreversibly adsorbed at the interface, as the energy necessary for desorption ranged from $10^{3}$ to $10^{4} k_{B} T$ in order of magnitude (Supporting Information 10). 


\subsubsection{Trehalose influence on the interfacial tension}

The interfacial tension for a suspension of non-lyophilized PLGA-PVA NPs in water (without trehalose) was significantly higher than for the suspension of lyophilized PLGA-PVA NPs water (with $150 \mathrm{mg} / \mathrm{mL}$ trehalose used as a cryoprotectant) $(14.4 \pm 0.4 \mathrm{mN} / \mathrm{m}$ versus $8.1 \pm$ $0.3 \mathrm{mN} / \mathrm{m}$ at $12 \mathrm{~h}$ ) (Figure $4 \mathrm{a})$. On the other hand, the interfacial tension of the suspension of non-lyophilized PLGA-PVA NPs in a solution of trehalose at $150 \mathrm{mg} / \mathrm{mL}$ (corresponding to the concentration of trehalose in the lyophilized NP suspension) was the same as the one obtained with lyophilized PLGA-PVA NPs in water (with $150 \mathrm{mg} / \mathrm{mL}$ trehalose). This means that the difference was not due to the lyophilization step but to the presence of trehalose in solution. Arnett et al. ${ }^{53}$ reported that some reputedly pure carbohydrates (trehalose, galactose and sucrose) were contaminated by surfactants. The purity of our trehalose sample was verified by a foaming technique that demonstrated the presence of surface active impurities. These impurities were not successfully removed from the solution. However, this was not a crucial issue in our study, considering that the emulsion prepared with trehalose alone $(150 \mathrm{mg} / \mathrm{mL})$ had a poor stability (Supporting Information 7). Moreover, the interfacial tension for a suspension of non-lyophilized PLGA-PVA NPs in water (without trehalose) was lower than that for a suspension of PLGA NPs in water underlining the crucial role played by PVA in the interfacial tension lowering. 


\subsubsection{Influence of the PVA chains sterically stabilizing the NPs on the interfacial tension}

As deduced from the quantification of PVA in NPs (see Supporting Information 2), $2 \mathrm{mg}$ of PVA were adsorbed at the surface of $25 \mathrm{mg}$ of PLGA-PVA NPs. We also observed that a PVA solution at $2 \mathrm{mg} / \mathrm{mL}$ led to a pronounced lowering of the interfacial tension (Figure 4a). This was not surprising, considering that PVA is known for its surfactant properties. ${ }^{54}$ It should be noted that no PVA aggregate was present in these solutions, as all the PVA aqueous solutions prepared in this study were at a concentration lower than the critical aggregation concentration (CAC) of the PVA (9.2 $\mathrm{mg} / \mathrm{mL})$ (Supporting Information 11).

To get a better insight into the effect of PVA sterically stabilizing the NPs, a bare PLGA NP suspension at $25 \mathrm{mg} / \mathrm{mL}$ was mixed with a solution of PVA at $2 \mathrm{mg} / \mathrm{mL}$. A decrease of the interfacial tension was observed compared to the PLGA NP suspension in water (Figure 4a). When bare PLGA NPs and free PVA are mixed in the same solution, free PVA chains adsorb more rapidly than PLGA NPs and lower the interfacial tension. Indeed, Stokes-Einstein diffusion coefficients $D$ for PVA chains in water and for non-lyophilized PLGA-PVA NPs could be

estimated from PVA radius of gyration $R_{g}$ in water $\left(R_{g} \sim 10 \mathrm{~nm}\right.$; see section 3.1) and from the

NP radius (see details in Supporting Information 10). For PVA in water, $D=3.7 \times 10^{-11} \mathrm{~m}^{2} / \mathrm{s}$ and for bare PLGA NPs, $D=2.5 \times 10^{-12} \mathrm{~m}^{2} / \mathrm{s}$. Nevertheless, the interfacial tension decrease was more limited compared to the PVA solution at $2 \mathrm{mg} / \mathrm{mL}$. A lower amount of PVA chains was 
able to adsorb at the oil/water interface in presence of PLGA NPs than when only PVA chains were present in the aqueous phase, since adsorbed PLGA NPs limited the adsorption or reconfiguration of PVA chains at the interface (see the schematic depictions of Fig 5a and 5c).

Finally, at the same concentration, PVA adsorbed onto PLGA-PVA NPs induced a more significant decrease in the interfacial tension than the mixture of free PVA and PLGA NPs (Figure 4a). More PVA chains were able to adsorb at the interface when they were previously adsorbed at the NP surface than when they were free in the aqueous phase in presence of PLGA NPs. This could be explained by a partial desorption of PVA from the particle surface when in contact with the oil phase (Figure 5b). Indeed, as previously observed (see section 3.1 Table 2), the PVA adsorbed at the NP surface made the surface more hydrophilic than PLGA. Interactions of PVA with the oil phase were thus less favorable than those of PLGA with the same phase. Our results suggest that PVA chains might partially detach from the NP surface at the water/Miglyol interface, and consequently favor the adsorption of the NPs at the interface. Once partially detached, these PVA chains or segments could adsorb at the oil/water interface in a more extended conformation and lower the interfacial tension. ${ }^{55}$ PVA chains at the NP surface and

directly in contact with Miglyol would contract. Indeed, the radius of gyration $R_{g}$ of a PVA coil $(\approx 10 \mathrm{~nm}$ in water as seen previously) was $\approx 2 \mathrm{~nm}$ in Miglyol (in a poor solvent, a compact conformation of the coil is obtained and $R_{g}=1 / \sqrt{6} \times N^{1 / 3} a$ ). This value is below the average 
distance between PVA chains at the particle suface $(\approx 5 \mathrm{~nm})$ calculated previously. The thickeness of the corona in contact with Miglyol should thus be in the order of magnitude of $R_{g}$. Besides, due to the contraction of the PVA chains at the particle surface when in contact with Miglyol, PLGA segments which are more hydrophobic were more exposed towards the oil phase. This would also explain why PVA did not affect the contact angle with Miglyol, whereas it did affect the contact angle with water (see section 3.1. Table 2). Figure 5d displays the asymmetrical conformation of one PLGA-PVA NP at the oil/water interface. Such asymmetrical conformation is similar to the one of core-shell NPs obtained with grafted polymers at liquid-liquid interfaces. ${ }^{24}$

Thus, PVA and, to a lesser extent, trehalose contributed to the differences in interfacial tension observed between lyophilized PLGA-PVA NPs and PLGA NPs.

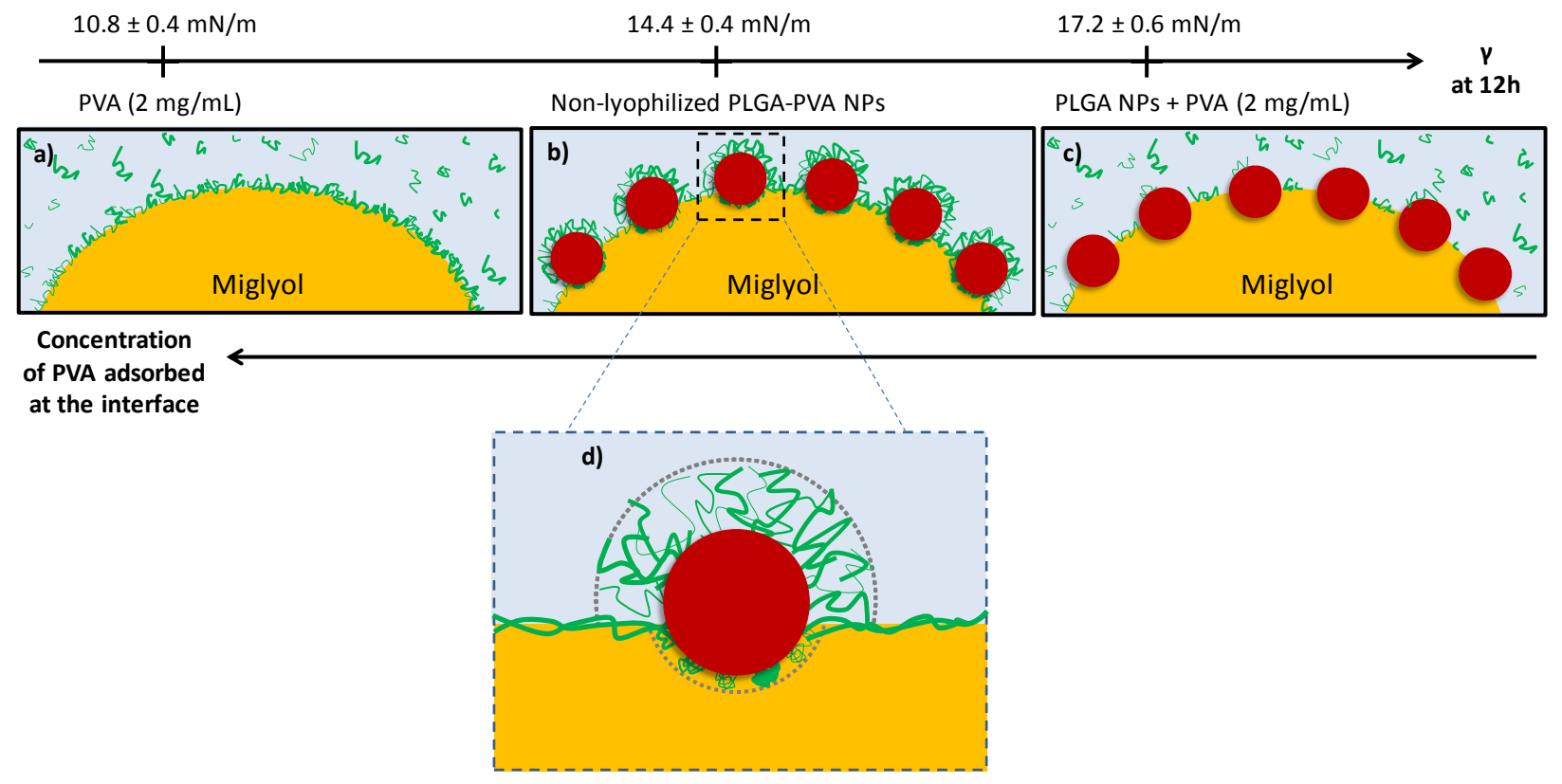


Figure 5. Schematic depiction of the interface between Miglyol and aqueous phase containing a) PVA in solution at $2 \mathrm{mg} / \mathrm{mL}$ b) PLGA-PVA NPs in suspension at $25 \mathrm{mg} / \mathrm{mL}$ c) PLGA NPs in suspension at $25 \mathrm{mg} / \mathrm{mL}$ in a solution of PVA at $2 \mathrm{mg} / \mathrm{mL}$ d) zoom of a PLGA-PVA NP at the oil/water interface.

\subsubsection{Interfacial rheology}

The elastic and viscous moduli of the different systems described above are shown in Figure 4b and 4c. Regardless of the type of NPs adsorbed (PLGA NPs, PLGA-PVA NPs with or without trehalose, lyophilized or not, PLGA NPs with free PVA), the elastic moduli were roughly the same and comparable to the elastic moduli measured without NPs adsorbed at the interface. Similar results were obtained for the viscous moduli of these interfaces. The lack of influence of the NPs on the interfacial moduli could be due to the mobility of the NPs at the interface. Indeed, if the NPs were able to move at the interface and to quickly rearrange when the interface was compressed or dilated, the rheological changes could not be detected with a tensiometer. Values of the interfacial modulus $\left|\mathrm{E}^{*}\right|$ ranged between 3 and $5 \mathrm{mN} / \mathrm{m}$ for all interfaces with NPs. These values were lower than the ones found in Gyulai and Kiss ${ }^{21}$ with a pendant drop tensiometer, where $\left|\mathrm{E}^{*}\right| \approx 10 \mathrm{mN} / \mathrm{m}$ at equilibrium for bare PLGA NPs (hydrodynamic diameter of $90 \mathrm{~nm}$ ) at air/water or octane/water interfaces, indicating highly compressible interfaces and well-separated NPs. This is also very different from oil/water interfaces covered with proteins, ${ }^{56}$ e.g. $\beta$ lactoglubulin (a small globular protein), which are very elastic $\left(\left|E^{*}\right|\right.$ and $E^{\prime} \approx 30 \mathrm{mN} / \mathrm{m}$ at 
equilibrium for $\beta$-lactoglubulin covering a Miglyol/water interface). ${ }^{57}$ Nelson et al. reported that even an interface that is highly covered by NPs could remain fluid. ${ }^{52}$ Thus, mobility of the NPs at the interface could explain that the NPs had no influence on the interfacial rheological properties. This mobility at the interface is governed by the interfacial diffusion coefficient. Rearrangement timescales for a displacement of one NP diameter were estimated between $10^{-2}$ to $50 \mathrm{~s}$, depending on interfacial diffusion coefficients (whose values could drop to $30 \%$ to $0.01 \%$ of their bulk values in oil or water). ${ }^{52}$ The rearrangement timescales could be compared to the droplet oscillation period of $60 \mathrm{~s}$. The absence of NP influence on interfacial rheological properties in our systems suggested a quick interfacial rearrangement, and thus a limited decrease of the interfacial diffusion coefficient compared to the bulk diffusion coefficient. Fluidity of the interface could possibly be attributed to the presence of a polymer shell surrounding the NPs, ${ }^{52}$ but, in our study, such mechanical properties also occured for bare PLGA NP without polymer shell. Indeed, because of their surface charge, PLGA NPs could act as electrostatic dipoles at the interface. ${ }^{58}$ Resulting electrostatic repulsions between NPs might prevent dynamic arrest and ensure NP mobility in absence of a steric stabilizer.

NP desorption phenomena could also explain the occurrence of a fluid interface, and such observations were reported in interface compression experiments. Though NP desorption is seemingly in contradiction with the principle of irreversibility of adsorption of the NPs at the interface ${ }^{59-61}$ a substantial compression $(e . g ., \approx 35 \% \text { decrease of the droplet area })^{62}$ could bring enough energy to force NPs to desorb from the interface. ${ }^{25,52,62,63}$ In our case, viscoelasticity was assessed through oscillatory variations of the droplet volume, i.e., through a series of sinusoidal 
expansion and compression of the droplet area. However, droplet area variations were small $( \pm 10 \%)$ and the energy necessary for desorption was high (Supporting Information 10). Moreover, surface pressure $v s$ droplet area during oscillations were reversible through expansion/compression cycles and did not reach any plateau, invalidating the NP desorption hypothesis.

\section{Conclusion}

Pickering emulsions using biodegradable and biocompatible components were successfully prepared using Miglyol as the oil, and bare PLGA NPs as stabilizers. They were compared with emulsions stabilized with PLGA-PVA NPs. Emulsions prepared with bare PLGA NPs displayed a better stability over 55 days. Interestingly, these emulsions exhibited very different macroscopic structures in terms of emulsion layer thickness and NP excess in the lower aqueous phase. They also displayed very different microscopic structures. Surprisingly, the co-existence of multiple $\mathrm{W} / \mathrm{O} / \mathrm{W}$ droplets and simple $\mathrm{O} / \mathrm{W}$ droplets was obtained with bare PLGA NPs after a single step of emulsification, whereas PLGA-PVA NPs led to simple O/W emulsions. Not only PVA chains led to a more hydrophilic surface as demonstrated by contact angle measurements, but they also lowered the interfacial tension. It is likely that PVA chains could partially desorb from the NPs to adsorb at the oil/water interface. This emphasizes the key role of the sterically stabilizing polymer present at the NP surface in the stabilization mechanism of Pickering emulsions. However, the rheological behavior of the interface was unaffected by the presence of NPs or their composition. Although further analysis is needed, this rheological behavior could be 
explained by the ability of NPs to move and quickly reorganize at the interface upon dilatation and compression. Moreover, the determination of the three-phase contact angle performed at oil/water interface on individual NPs (e.g. with FreSCA cryo-SEM $)^{64}$ could also provide valuable information to further explain the microstructure of the emulsions. Finally, this system offers the possibility to control the structure of an emulsion by the nature of the NPs that stabilize it. Such Pickering emulsions using PLGA NPs appear as very promising systems for pharmaceutical and cosmetic applications and could be extended to other biocompatible oils.

\section{ASSOCIATED CONTENT}

Supporting Information 1: NP preparation

Supporting Information 2: Amount of PVA adsorbed on the surface of the NPs

Supporting Information 3: Characterization of PLGA-PVA NP surface

Supporting Information 4: AFM imaging of the layers of NPs

Supporting Information 5: NP hydrophobicity measurements

Supporting Information 6: Examples of Turbiscan curves obtained for the emulsion stabilized by lyophilized PLGA-PVA NPs 
Supporting Information 7: Comparison of the stability of emulsions stabilized either by lyophilized PLGA-PVA NPs, by non-lyophilized PLGA-PVA NPs or by a trehalose solution

Supporting Information 8: Confocal microscopy images of emulsions for different water/oil ratios

Supporting Information 9: Values of interfacial tension and interfacial moduli at $12 \mathrm{~h}$

Supporting Information 10: Modelisation of the adsorption kinetics of NPs at the oil/water interface

Supporting Information 11: Measurement of the critical aggregation concentration (CAC) of PVA

\section{ACKNOWLEDGMENT}

Nicolas Huang thanks the Agence Nationale de la Recherche (ANR) for its support through a Young Researchers grant (ANR-16-CE09-0003). Claire Albert acknowledges support from the Ministère de 1'Education Nationale, de l'Enseignement Supérieur et de la Recherche for her Ph.D grant. Authors thank the "Région Ile-de-France » for the purchase of the confocal microscope. Authors are grateful to Dr Bertrand Fournier for his help on computer solving of adsorption energy equations and to reviewers of the manuscript for constructive comments that have helped improving the quality of the article. 


\section{ABBREVIATIONS}

AFM, atomic force microscope; CAC, critical aggregation concentration; D, day or days; |E*|, absolute value of the complex dilatational modulus; E', interfacial elastic modulus; E', interfacial viscous modulus; Miglyol, Miglyol 812 N; NPs, nanoparticles; O/W, oil in water; PdI, Polydispersity Index; PLGA: poly(lactic-co-glycolic) acid; PVA, poly(vinyl alcohol); Rhod, rhodamine; $\mathrm{W} / \mathrm{O}$, water in oil; $\mathrm{W} / \mathrm{O} / \mathrm{W}$, water in oil in water

\section{REFERENCES}

(1) Marti-Mestres, G.; Nielloud, F. Emulsions in Health Care Applications-An Overview. $J$. Dispers. Sci. Technol. 2002, 23 (1-3), 419-439.

(2) Tadros, T. F. Emulsion Formation and Stability; Wiley-VCH-Verl: Weinheim, 2013.

(3) Scherlund, M.; Malmsten, M.; Brodin, A. Stabilization of a Thermosetting Emulsion System Using Ionic and Nonionic Surfactants. Int. J. Pharm. 1998, 173 (1), 103-116.

(4) Cserháti, T.; Forgács, E.; Oros, G. Biological Activity and Environmental Impact of Anionic Surfactants. Environ. Int. 2002, 28 (5), 337-348.

(5) Branco, N.; Lee, I.; Zhai, H.; Maibach, H. I. Long-Term Repetitive Sodium Lauryl SulfateInduced Irritation of the Skin: An in Vivo Study. Contact Dermatitis 2005, 53 (5), 278284.

(6) Lémery, E.; Briançon, S.; Chevalier, Y.; Bordes, C.; Oddos, T.; Gohier, A.; Bolzinger, M.A. Skin Toxicity of Surfactants: Structure/Toxicity Relationships. Colloids Surf. Physicochem. Eng. Asp. 2015, 469, 166-179.

(7) Aveyard, R.; Binks, B. P.; Clint, J. H. Emulsions Stabilised Solely by Colloidal Particles. Adv. Colloid Interface Sci. 2003, 100, 503-546. 
(8) Chevalier, Y.; Bolzinger, M.-A. Emulsions Stabilized with Solid Nanoparticles: Pickering Emulsions. Colloids Surf. Physicochem. Eng. Asp. 2013, 439, 23-34.

(9) Schmitt, V.; Destribats, M.; Backov, R. Colloidal Particles as Liquid Dispersion Stabilizer: Pickering Emulsions and Materials Thereof. Comptes Rendus Phys. 2014, 15 (8-9), 761774.

(10) Pickering, S. U. Emulsions. J Chem Soc 1907, 91, 2001-2021.

(11) Ramsden, W. Separation of Solids in the Surface-Layers of Solutions and "Suspensions" (Observations on Surface-Membranes, Bubbles, Emulsions, and Mechanical Coagulation). -- Preliminary Account. Proc R Soc Lond 1903, 72, 156-164.

(12) Yang, Y.; Fang, Z.; Chen, X.; Zhang, W.; Xie, Y.; Chen, Y.; Liu, Z.; Yuan, W. An Overview of Pickering Emulsions: Solid-Particle Materials, Classification, Morphology, and Applications. Front. Pharmacol. 2017, 8.

(13) Makadia, H. K.; Siegel, S. J. Poly Lactic-Co-Glycolic Acid (PLGA) as Biodegradable Controlled Drug Delivery Carrier. Polymers 2011, 3 (4), 1377-1397.

(14) Handbook of Pharmaceutical Excipients, 6. ed.; Rowe, R. C., Ed.; APhA, (PhP) Pharmaceutical Press, 2009.

(15) Astete, C. E.; Sabliov, C. M. Synthesis and Characterization of PLGA Nanoparticles. $J$. Biomater. Sci. Polym. Ed. 2006, 17 (3), 247-289.

(16) Whitby, C. P.; Lim, L. H.; Ghouchi Eskandar, N.; Simovic, S.; Prestidge, C. A. Poly(lactic-Co-Glycolic Acid) as a Particulate Emulsifier. J. Colloid Interface Sci. 2012, $375(1), 142-147$.

(17) Qi, F.; Wu, J.; Sun, G.; Nan, F.; Ngai, T.; Ma, G. Systematic Studies of Pickering Emulsions Stabilized by Uniform-Sized PLGA Particles: Preparation and Stabilization Mechanism. J Mater Chem B 2014, 2 (43), 7605-7611.

(18) Deschamps, F.; Harris, K. R.; Moine, L.; Li, W.; Tselikas, L.; Isoardo, T.; Lewandowski, R. J.; Paci, A.; Huang, N.; de Baere, T.; Salem R., Larson A. C. Pickering-Emulsion for Liver Trans-Arterial Chemo-Embolization with Oxaliplatin. Cardiovasc. Intervent. Radiol. 2018, 41 (5), 781-788. 
(19) Stolnik, S.; Garnett, M. C.; Davies, M. C.; Illum, L.; Bousta, M.; Vert, M.; Davis, S. S. The Colloidal Properties of Surfactant- Free Biodegradable Nanospheres from poly(BMalic Acid-Co-Benzyl Malate)s and Poly(lactic Acid-Co-Glycolide). Colloids Surf. Physicochem. Eng. Asp. 1995, 97.

(20) Grabowski, N.; Hillaireau, H.; Vergnaud, J.; Tsapis, N.; Pallardy, M.; Kerdine-Römer, S.; Fattal, E. Surface Coating Mediates the Toxicity of Polymeric Nanoparticles towards Human-like Macrophages. Int. J. Pharm. 2015, 482 (1-2), 75-83.

(21) Gyulai, G.; Kiss, É. Interaction of Poly(lactic- Co -Glycolic Acid) Nanoparticles at Fluid Interfaces. J. Colloid Interface Sci. 2017, 500, 9-19.

(22) Mura; Fattal, E.; Nicolas; Hillaireau, H.; Gueutin; Le Droumaguet; Zanna; Tsapis. Influence of Surface Charge on the Potential Toxicity of PLGA Nanoparticles towards Calu-3 Cells. Int. J. Nanomedicine 2011, 2591.

(23) Grabowski, N.; Hillaireau, H.; Vergnaud, J.; Santiago, L. A.; Kerdine-Romer, S.; Pallardy, M.; Tsapis, N.; Fattal, E. Toxicity of Surface-Modified PLGA Nanoparticles toward Lung Alveolar Epithelial Cells. Int. J. Pharm. 2013, 454 (2), 686-694.

(24) Isa, L.; Amstad, E.; Schwenke, K.; Del Gado, E.; Ilg, P.; Kröger, M.; Reimhult, E. Adsorption of Core-Shell Nanoparticles at Liquid-liquid Interfaces. Soft Matter 2011, 7 (17), 7663.

(25) Garbin, V.; Crocker, J. C.; Stebe, K. J. Nanoparticles at Fluid Interfaces: Exploiting Capping Ligands to Control Adsorption, Stability and Dynamics. J. Colloid Interface Sci. 2012, 387 (1), 1-11.

(26) Mengual, O.; Meunier, G.; Cayré, I.; Puech, K.; Snabre, P. TURBISCAN MA 2000: Multiple Light Scattering Measurement for Concentrated Emulsion and Suspension Instability Analysis. Talanta 1999, 50 (2), 445-456.

(27) Particle Size Analysis - Dynamic Light Scattering (DLS) ISO 22412; ISO Standard Document; 2008.

(28) Vauthier, C.; Schmidt, C.; Couvreur, P. Measurement of the Density of Polymeric Nanoparticulate Drug Carriers by Isopycnic Centrifugation. J. Nanoparticle Res. 1999, 1, 411-418. 
(29) Jin, W.; Liu, G.; Xu, N. Organic-Inorganic Composite Membranes for Molecular Separation, World Scientific.; Series on Chemical Engineering; 2017; Vol. 5.

(30) Sahoo, S. K.; Panyam, J.; Prabha, S.; Labhasetwar, V. D. Residual Polyvinyl Alcohol Associated with poly(D,L-Lactide-Co-Glycolide) Nanoparticles Affects Their Physical Properties and Cellular Uptake. J. Controlled Release 2002, 82, 105-114.

(31) Liu, J.; Huang, X.; Lu, L.; Li, M.; Xu, J.; Deng, H. Turbiscan Lab® Expert Analysis of the Biological Demulsification of a Water-in-Oil Emulsion by Two Biodemulsifiers. $J$. Hazard. Mater. 2011, 190 (1-3), 214-221.

(32) Sandell, E. Industrial Aspect of Pharmaceutics; Swedish pharmaceutical press, 1993.

(33) Binks, B. P.; Clint, J. H.; Dyab, A. K. F.; Fletcher, P. D. I.; Kirkland, M.; Whitby, C. P. Ellipsometric Study of Monodisperse Silica Particles at an Oil-Water Interface. Langmuir 2003, 19 (21), 8888-8893.

(34) Arditty, S.; Schmitt, V.; Giermanska-Kahn, J.; Leal-Calderon, F. Materials Based on SolidStabilized Emulsions. J. Colloid Interface Sci. 2004, 275 (2), 659-664.

(35) Gao, Q.; Wang, C.; Liu, H.; Chen, Y.; Tong, Z. Dual Nanocomposite Multihollow Polymer Microspheres Prepared by Suspension Polymerization Based on a Multiple Pickering Emulsion. Polym Chem 2010, 1 (1), 75-77.

(36) Zou, S.; Wang, C.; Gao, Q.; Tong, Z. Surfactant-Free Multiple Pickering Emulsions Stabilized by Combining Hydrophobic and Hydrophilic Nanoparticles. J. Dispers. Sci. Technol. 2013, 34 (2), 173-181.

(37) Rymaruk, M. J.; Thompson, K. L.; Derry, M. J.; Warren, N. J.; Ratcliffe, L. P. D.; Williams, C. N.; Brown, S. L.; Armes, S. P. Bespoke Contrast-Matched Diblock Copolymer Nanoparticles Enable the Rational Design of Highly Transparent Pickering Double Emulsions. Nanoscale 2016, 8 (30), 14497-14506.

(38) Binks, B. P.; Rodrigues, J. A. Types of Phase Inversion of Silica Particle Stabilized Emulsions Containing Triglyceride Oil. Langmuir 2003, 19 (12), 4905-4912.

(39) Binks, B. P.; Fletcher, P. D. I.; Holt, B. L.; Beaussoubre, P.; Wong, K. Phase Inversion of Particle-Stabilised Perfume Oil-water Emulsions: Experiment and Theory. Phys. Chem. Chem. Phys. 2010, 12 (38), 11954. 
(40) White, K. A.; Schofield, A. B.; Wormald, P.; Tavacoli, J. W.; Binks, B. P.; Clegg, P. S. Inversion of Particle-Stabilized Emulsions of Partially Miscible Liquids by Mild Drying of Modified Silica Particles. J. Colloid Interface Sci. 2011, 359 (1), 126-135.

(41) Binks, B. P.; Whitby, C. P. Silica Particle-Stabilized Emulsions of Silicone Oil and Water: Aspects of Emulsification. Langmuir 2004, 20 (4), 1130-1137.

(42) Zhu, Y.; Sun, J.; Yi, C.; Wei, W.; Liu, X. One-Step Formation of Multiple Pickering Emulsions Stabilized by Self-Assembled Poly(dodecyl Acrylate-Co-Acrylic Acid) Nanoparticles. Soft Matter 2016, 12 (36), 7577-7584.

(43) Chen, J.; Vogel, R.; Werner, S.; Heinrich, G.; Clausse, D.; Dutschk, V. Influence of the Particle Type on the Rheological Behavior of Pickering Emulsions. Colloids Surf. Physicochem. Eng. Asp. 2011, 382 (1-3), 238-245.

(44) He, Y.; Wu, F.; Sun, X.; Li, R.; Guo, Y.; Li, C.; Zhang, L.; Xing, F.; Wang, W.; Gao, J. Factors That Affect Pickering Emulsions Stabilized by Graphene Oxide. ACS Appl. Mater. Interfaces 2013, 5 (11), 4843-4855.

(45) Tang, M.; Wu, T.; Xu, X.; Zhang, L.; Wu, F. Factors That Affect the Stability, Type and Morphology of Pickering Emulsion Stabilized by Silver Nanoparticles/Graphene Oxide Nanocomposites. Mater. Res. Bull. 2014, 60, 118-129.

(46) Nonomura, Y.; Kobayashi, N.; Nakagawa, N. Multiple Pickering Emulsions Stabilized by Microbowls. Langmuir 2011, 27 (8), 4557-4562.

(47) Read, E. S.; Fujii, S.; Amalvy, J. I.; Randall, D. P.; Armes, S. P. Effect of Varying the Oil Phase on the Behavior of $\mathrm{pH}$-Responsive Latex-Based Emulsifiers: Demulsification versus Transitional Phase Inversion. Langmuir 2004, 20 (18), 7422-7429.

(48) Tu, F.; Lee, D. One-Step Encapsulation and Triggered Release Based on Janus ParticleStabilized Multiple Emulsions. Chem Commun 2014, 50 (98), 15549-15552.

(49) Clegg, P. S.; Tavacoli, J. W.; Wilde, P. J. One-Step Production of Multiple Emulsions: Microfluidic, Polymer-Stabilized and Particle-Stabilized Approaches. Soft Matter 2016, 12 (4), 998-1008. 
(50) Groeneweg, F.; Agterof, W. G. M.; Jaeger, P.; Janssen, J. J. M.; Wieringa, J. A.; Klahn, J. K. On the Mechanism of the Inversion of Emulsions. Chem. Eng. Res. Des. 1998, 76, 5563.

(51) Bizmark, N.; Ioannidis, M. A. Effects of Ionic Strength on the Colloidal Stability and Interfacial Assembly of Hydrophobic Ethyl Cellulose Nanoparticles. Langmuir 2015, 31 (34), 9282-9289.

(52) Nelson, A.; Wang, D.; Koynov, K.; Isa, L. A Multiscale Approach to the Adsorption of Core-shell Nanoparticles at Fluid Interfaces. Soft Matter 2015, 11 (1), 118-129.

(53) Arnett, E. M.; Harvey, N.; Johnson, E. A.; Johnston, D. S.; Chapman, D. No Phospholipid Monolayer-Sugar Interactions. Biochemistry (Mosc.) 1986, 25 (18), 5239-5242.

(54) Blehn, G. F.; Ernsberger, M. L. Polyvinyl Alcohol as an Emulsifying Agent. Ind. Eng. Chem. 1948, 40 (8), 1449-1453.

(55) Isa, L.; Calzolari, D. C. E.; Pontoni, D.; Gillich, T.; Nelson, A.; Zirbs, R.; Sánchez-Ferrer, A.; Mezzenga, R.; Reimhult, E. Core-shell Nanoparticle Monolayers at Planar Liquidliquid Interfaces: Effects of Polymer Architecture on the Interface Microstructure. Soft Matter 2013, 9 (14), 3789.

(56) Benjamins, J.; Lucassen-Reynders, E. H. Surface Dilational Rheology of Proteins Adsorbed at Air/Water and Oil/Water Interfaces. In Proteins at Liquid Interfaces; Studies in Interface Science; Dietmar Möbius, Reinhard Miller, 1998; Vol. 7, pp 341-384.

(57) Ali, A.; Le Potier, I.; Huang, N.; Rosilio, V.; Cheron, M.; Faivre, V.; Turbica, I.; Agnely, F.; Mekhloufi, G. Effect of High Pressure Homogenization on the Structure and the Interfacial and Emulsifying Properties of $\beta$-Lactoglobulin. Int. J. Pharm. 2018, 537 (1-2), $111-121$.

(58) Dani, A.; Keiser, G.; Yeganeh, M.; Maldarelli, C. Hydrodynamics of Particles at an OilWater Interface. Langmuir 2015, 31 (49), 13290-13302.

(59) Binks, B. P.; Kirkland, M. Interfacial Structure of Solid-Stabilised Emulsions Studied by Scanning Electron Microscopy. Phys. Chem. Chem. Phys. 2002, 4 (15), 3727-3733.

(60) Binks, B. P.; Horozov, T. S. Colloidal Particles at Liquid Interfaces; Cambridge University Press, 2006. 
(61) Pieranski, P. Two-Dimensional Interfacial Colloidal Crystals. Phys. Rev. Lett. 1980.

(62) Garbin, V.; Crocker, J. C.; Stebe, K. J. Forced Desorption of Nanoparticles from an OilWater Interface. Langmuir 2012, 28 (3), 1663-1667.

(63) Zell, Z. A.; Isa, L.; Ilg, P.; Leal, L. G.; Squires, T. M. Adsorption Energies of Poly(ethylene Oxide)-Based Surfactants and Nanoparticles on an Air-Water Surface. Langmuir 2014, 30 (1), 110-119.

(64) Isa, L.; Lucas, F.; Wepf, R.; Reimhult, E. Measuring Single-Nanoparticle Wetting Properties by Freeze-Fracture Shadow-Casting Cryo-Scanning Electron Microscopy. Nat. Commun. 2011, 2, 438.

\section{Table of Contents Graphic}

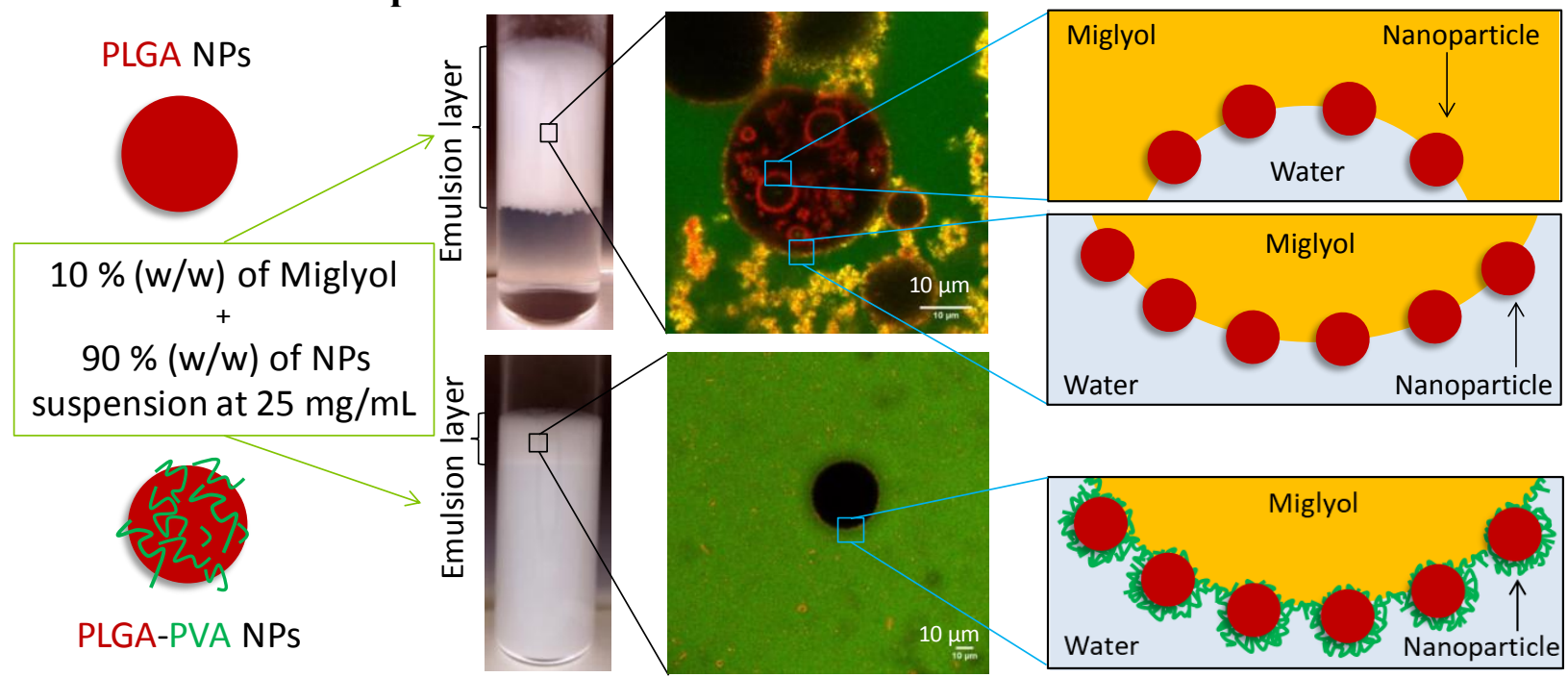

Emulsions stabilized with bare poly(lactic-co-glycolic acid) (PLGA) nanoparticles (NPs) demonstrated very different structures at macroscopic, microscopic and interfacial scales compared to emulsions stabilized with PLGA-PVA NPs, i.e. with poly(vinyl alcohol) (PVA) as NP stabilizer. 